\title{
Anticholesterolemic, Antitriglyceridemic and Antioxidative Activity Effect of Umbelliferone (Coumarin) in Streptozocin Treated Diabetic Rats
}

\author{
K. R. Anjan Kumar ${ }^{\text {* }}$, M. L. Satyanarayana ${ }^{1}$, H. D. Narayanaswamy ${ }^{1}$, \\ Suguna Rao ${ }^{1}$, N. Prakash ${ }^{2}$ and P. T. Ramesh ${ }^{3}$
}

${ }^{1}$ Department of Veterinary Pathology, ${ }^{2}$ Department of Veterinary Pharmacology and Toxicology, ${ }^{3}$ Department of TVCC, Veterinary college, Veterinary college, Hebbal, Bengaluru-560024, India

*Corresponding author

\section{Keywords}

Anticholesterolemic, Antitriglyceridemic and Antioxidative Activity, Umbelliferone

Article Info

Accepted:

04 August 2020

Available Online:

10 September 2020

A B S T R A C T

The present study was designed to evaluate the role of umbelliferone in alleviating hyperlipidemia and oxidative damage in streptozotocin induced diabetes mellitus in wistar albino rats. Six groups of rats were used as control, diabetic control, umbelliferone at 20 $\mathrm{mg} / \mathrm{kg}$ b.wt., umbelliferone at $40 \mathrm{mg} / \mathrm{kg}$ b.wt. and combination of glibenclamide and umbelliferone at $20 \mathrm{mg} / \mathrm{kg} \mathrm{b}$. wt., was used in the study. Diabetes was induced in male Wistar rats by administering streptozocin at $45 \mathrm{mg} / \mathrm{kg}$ b. wt. in citrate buffer, intraperitoneally. Serum estimation of triglyceride and cholesterol as well as anti-oxidant profile such as SOD, CAT and GPx was evaluated on $15^{\text {th }}, 30^{\text {th }}$ and $45^{\text {th }}$ day of experiment. The control rats showed normal values throughout the experimental period. The diabetic rats showed significant hypercholesterolemia and hypertriglyceridemia with reduced tissue anti-oxidant levels. Whereas, the umbelliferone treated groups showed significant decrease in triglyceride and cholesterol levels as well as increased the anti-oxidant profiles by the end of the experimental period. Thus, our results show that umbelliferone alone $(20 \mathrm{mg} / \mathrm{kg}$. b. wt. and $40 \mathrm{mg} / \mathrm{kg}$. b. wt.) possessed anticholesterolemic and anti-triglyceridemic properties. The significant improvement in anti-oxidant profile in the current study could be attributed to bioactivity of umbelliferone and were statistically comparable with the glibenclamide treated group.

\section{Introduction}

Diabetes mellitus (DM) is an annihalatory chronic metabolic disorder that has attained the status of a global pandemic across Asia, Latin America and Africa ${ }^{1}$. The current global prevalence of diabetes is estimated at 415 million and is projected to increase to 642 million by 2040 , if preventive measures are not put in place. Over $60 \%$ of the world's population with diabetes resides in Asia, of which India and China contribute the largest ${ }^{2}$.The first line of treatment in DM includes the use of oral hypoglycemic agents. However, they are associated with several side effects and are inadequate to alter the course of diabetic complications ${ }^{3}$. Herbal agents are prescribed widely because of their 
effectiveness, fewer side effects and relatively low cost ${ }^{4}$. The polyherbal formulation could be useful for diabetic patients on Glibenclamide therapy, to obtain better control over the blood glucose and lipid levels ${ }^{5}$

Umbelliferone (UMB), a derivative of coumarin, benzopyrene in nature and is mainly extracted from Citrus aurantium ${ }^{6}$ and is a pharmacologically active agent. Umbelliferone has been shown to exhibit pharmacological activities against various health-related conditions, including conditions related to pro-oxidants and reactive oxygen species such as inflammation, degenerative diseases, microbial infections, and cancer cells ${ }^{7}$.

Several of the plant-derived phenolic coumarins play a role as dietary antioxidants ${ }^{8}$. The parent compound coumarin has been reported to reduce or decrease blood glucose, elevated plasma insulin, protein profile, and cause hypolipidemic effect ${ }^{9}$.In addition, UMB confers cells to resist oxidative stress by facilitating biosynthesis of superoxide dismutase (SOD), glutathione (GSH) and (CAT) catalase ${ }^{10}$.Apart from the antioxidant activity, UMB was reported to ameliorate hypertriglyceridemia and hyperglycemia partly by improving glucose tolerance, modulating hepatic lipid metabolism and the antioxidant defense system along with increasing adiponectin levels ${ }^{11}$. Hence, the present study was carried out to evaluate the anti-oxidative, anti-hyperlipidaemic and hepatoprotective efficacy of UMB, (a coumarin compound) in serum and hepatic tissue of STZ induced diabetic rats.

\section{Materials and Methods}

Animals: Genetically normal adult male Wistar albino rats weighing 170-200 g were procured and were maintained under standard laboratory conditions and offered ad libitum of standard commercial rat feed (Amruth Feeds, Bangalore) and clean reverse osmosis drinking water. The experiment was carried out after obtaining permission from Institutional Animal Ethics Committee, Veterinary College, Hebbal, Bengaluru vide Ref No. VCS / IAEC/ 23/ 2017-18 dt 22.12.2017.

Chemicals: Streptozotocin (STZ) and Umbelliferone, (Cat No.: H24003) was purchased from Sigma chemicals, USA. Umbelliferone (7-hydroxycoumarin,). Glibenclamide (Glyenil ${ }^{\circledR}, 5 \mathrm{mg}$ ) was procured from a local chemist. All the other chemicals were of analytical grade obtained from Merck, Trivitron, India and HIMEDIA, India

\section{Experimental induction of diabetes} mellitus (DM)

The rats were fasted overnight and injected with freshly prepared streptozotocin (Sigma chemicals, USA) at a dose of $45 \mathrm{mg} / \mathrm{kg} \mathrm{b}$. wt. intraperitoneally in $0.09 \mathrm{M}$ citrate buffer solution procured from M/s Sigma chemicals, USA (Cat- C2488), having a pH 4.5 to induce diabetes mellitus (Babu and Prince, 2004). The control Group I control received citrate buffer alone. The diabetic state was confirmed by estimating the random glucose levels after 72 hours of STZ injection using Accu-chek ${ }^{\circledR}$ (M/s Roche, India) using strips. The blood was collected from the tail vein by using an Insulin syringe bearing 31' $\mathrm{G}$ needle. The animals with a glucose level above $200 \mathrm{mg} / \mathrm{dl}$ were considered diabetic and selected for the study.

\section{Experimental design}

The rats were randomly divided into six different groups with eighteen animals in each as given below. The UMB and glibenclamide were administered orally by a gavaging 
needle once a day using vehicle solution. The rats of Group I and II were gavaged only with distilled water.

\begin{tabular}{|l|l|}
\hline Group I (NC) & Normal control: \\
\hline Group II (DC) & Diabetic control: R.O water \\
\hline Group III (GC) & $\begin{array}{l}\text { Glibenclamide (GC) @600 } \mu \mathrm{g} / \mathrm{kg} \\
\text { b. wt. }\end{array}$ \\
\hline Group IV (U-20) & UMB @ $20 \mathrm{mg} / \mathrm{kg} \mathrm{b.} \mathrm{wt.}$ \\
\hline Group V (U-40) & UMB @ $40 \mathrm{mg} / \mathrm{kg} \mathrm{b.} \mathrm{wt.}$ \\
\hline $\begin{array}{l}\text { Group VI (U-20 + } \\
\text { GC) }\end{array}$ & $\begin{array}{l}\text { UMBandGC @ 20 mg/kg body } \\
\text { and } 600 \mu \mathrm{g} / \mathrm{kg} \text { b. wt. }\end{array}$ \\
\hline
\end{tabular}

To study the progressive effects of the treatments given to different groups, two rats from each group were sacrificed humanely under ketamine anaesthesia on $15^{\text {th }}$ and $30^{\text {th }}$ and the remaining rats on the $45^{\text {th }}$ day of experimentation. Blood samples were collected in both EDTA and serum vacutainer containing clot activator. The serum was subjected to serum chemistry analysis viz; triglycerides and cholesterol. During necropsy, a piece of liver was collected in icecold normal saline for the estimation of antioxidant enzymes super oxide dismutase (SOD), catalase (CAT) and glutathione peroxidase (GPx) and stored in $-80{ }^{\circ} \mathrm{C}$ deep freezer till further analysis.

\section{Biochemical Determinations}

Serum triglyceride and cholesterol was estimated as per the kit manufacturers (Trivitron, Labsystems) protocol. SOD from liver tissues was estimated as per Marklund ${ }^{12}$.Catalase was estimated by the method described by Caliborne ${ }^{13}$.Glutathione peroxidase was determined by the method described by Rotruck ${ }^{14}$.

\section{Statistical analysis}

Values given in the table as means \pm SD for six rats for each group on Day 15, 30 and 45. Data's were analyzed by two-way analysis of Variance (ANOVA) using Prism 7.0. The limit of statistical significance was set up at $\mathrm{p}$ $\leq 0.05$.

\section{Results and Discussion}

\section{Serum cholesterol}

The mean $( \pm$ SE) serum cholesterol levels are presented in the Table 1 and Fig: 1.0.The mean $( \pm \mathrm{SE})$ serum cholesterol level in the normal control animals remained normal throughout the experimental period. The diabetic rats of Group II revealed a significant increase $(\mathrm{P} \leq 0.001)$ in the serum cholesterol level from day 15 to day 45 of the experiment when compared with the remaining treatment groups at all intervals of the study. There was a significant $(\mathrm{p} \leq 0.001)$ reduction in the serum cholesterol values of all the treatment groups from Day 30 to Day 45 of the experimental period.

In Group V and Group VI, the mean serum cholesterol values remained non-significant $(\mathrm{P}>0.05)$ on $30^{\text {th }}$ and $45^{\text {th }}$ day when compared to normal control rats. This decline in the mean values did not differ significantly between the groups on all intervals of the experimental period.

\section{Serum triglycerides}

The mean $( \pm \mathrm{SE})$ serum triglycerides level levels are presented in the table 2.0 and Fig: 2.The normal control rats showed no significant $(\mathrm{P} \geq 0.05)$ variation in triglyceride levels throughout the experiment. The diabetic rats of Group II revealed a significant increase $(\mathrm{P} \leq 0.001)$ in the serum triglyceride levels when compared to those of normal control rats at all tested intervals of the experimental period. In Group III (gliben clamide treatment group) rats, In group III, IV, V and VI treated rats, showed a progressive decline in the mean values and were significantly reduced $(\mathrm{P} \leq 0.001)$ 
compared to that of diabetic control rats on Day 30 and Day 45 of treatment and were comparable to that of normal control values on $45^{\text {th }}$ day of post-treatment. The mean values of all the treated groups were comparable to each other on Day 45 and when compared to normal control group, the mean values did not differ significantly.

\section{Antioxidants: Superoxide dismutase (SOD)}

The mean $( \pm$ SE) SOD activity levels are presented in the table 2.0 and Fig: 2.The mean $( \pm$ SE) SOD activity in the normal control group of rats showed no significant throughout the experimental study.In Group II, the mean $( \pm$ SE) levels of SOD activity (diabetic control) in rats showed a progressive decrease from day 15 onwards and values were significantly lower $(p \leq 0.05)$ compared to normal control group of rats.

The mean $( \pm$ SE) SOD activity of Group III (rats treated with Glibenclamide) showed a significant improvement in the SOD with $\mathrm{P} \leq$ 0.05 on day 45 of the study compared to diabetic control. In group IV (Umbelliferone (a) 20mg/kg b. wt.) the values were comparable to diabetic control values on day 15, 30 and day 45. Besides, the results were compared with those of glibenclamide treated rats throughout the experimental period except on day $45(\mathrm{P} \geq 0.05)$.

The mean $( \pm$ SE) SOD activity of Group V rats, the values were found to be significantly improved with $\mathrm{P} \leq 0.01$ only on day 45 of the study and Group VI showed improvement with SOD activity with mean values were statistically higher $(\mathrm{P} \leq 0.05)$ compared to the diabetic control group on $45^{\text {th }}$ day, when compared to diabetic control. The values were comparable with those of glibenclamide treated rats throughout the experimental period ( $\mathrm{p} \geq 0.05$ ). However, sod activity was not similar to control group, but were comparable at all intervals tested with glibenclamide treated groups or when tested at $\mathrm{P}>0.05$.

\section{Catalase (CAT)}

The mean $( \pm$ SE) CAT activity levels are presented in the table 4 and Fig: 4.0.The mean $( \pm$ SE) CAT activity in the normal control animals showed no significant change in the mean CAT values throughout the experiment. In group II, the mean ( \pm SE) CAT activity values showed a decrease, which was highly significant $(\mathrm{P} \leq 0.001)$ in comparison with those of normal control group. On $45^{\text {th }}$ day of the experiment, the mean CAT activity levels were comparable between the treated groups. However, there was no significant difference in the values when compared to Glibenclamide and were comparable in all intervals of the study.

\section{Glutathione peroxidase (GPx)}

The mean $( \pm$ SE) GPx activity levels are presented in the table 5 and Fig: 5.0.The mean $( \pm \mathrm{SE})$ value of GPx activity in the normal control animals showed no significant change in the mean GPx activity throughout the experiment. The mean $( \pm \mathrm{SE})$ value of GPx activity of diabetic control rats progressively decreased and was significant $(\mathrm{P} \leq 0.01)$ in comparison with those of normal control group. The rats of glibenclamide treated group showed a consistent increase in the mean ( \pm SE) GPx activity which was a moderate improvement in the mean GPx activity when compared to diabetic control and normal control group. The mean $( \pm$ SE) GPx activity of the rats in all the treatment groups showed an improvement from $15^{\text {th }}$ to $45^{\text {th }}$ day and the values of GPx activity were higher compared to diabetic control animals on $45^{\text {th }}$ day and were comparable between the groups on all tested intervals of the experimental period. 
Table.1 The Mean $( \pm$ SE) serum cholesterol $(\mathrm{mg} / \mathrm{dL})$ values of treatment and control groups at different intervals of time

\begin{tabular}{|l|c|c|c|}
\hline \multirow{2}{*}{\multicolumn{1}{|c|}{ Groups }} & \multicolumn{3}{c|}{ Serum cholesterol - Days post treatment } \\
\cline { 2 - 4 } & Day 15 & Day 30 & Day 45 \\
\hline Group I (NC) & $86.8 \pm 2.4^{\mathrm{aX}}$ & $87.4 \pm 3.33^{\mathrm{aX}}$ & $88.5 \pm 1.78^{\mathrm{aX}}$ \\
\hline Group II (DC) & $112.6 \pm 3.02^{\mathrm{bX}}$ & $125.8 \pm 5.26^{\mathrm{bY}}$ & $142.4 \pm 3.48^{\mathrm{bZ}}$ \\
\hline Group III (GC) & $119.5 \pm 2.73^{\mathrm{bX}}$ & $116.0 \pm 4.09^{\mathrm{cX}}$ & $94.4 \pm 1.78^{\mathrm{aY}}$ \\
\hline Group IV (U20) & $112.9 \pm 2.19^{\mathrm{bX}}$ & $107.5 \pm 2.95^{\mathrm{cXY}}$ & $97.1 \pm 3.02^{\mathrm{aY}}$ \\
\hline Group V (U40) & $108.2 \pm 2.10^{\mathrm{bX}}$ & $100.5 \pm 2.17^{\mathrm{acX}}$ & $95.6 \pm 1.90^{\mathrm{aX}}$ \\
\hline Group VI (U20 & $107.6 \pm 2.70^{\mathrm{bX}}$ & $99.25 \pm 2.71^{\mathrm{acXY}}$ & $94.6 \pm 2.03^{\mathrm{aY}}$ \\
\hline
\end{tabular}

Values bearing different superscripts between rows within a column and capital letters within column vary significantly $(\mathrm{p} \leq 0.05)$

Table.2 The Mean $( \pm \mathrm{SE})$ serum triglycerides $(\mathrm{mg} / \mathrm{dL})$ values of treatment and control groups at different intervals of time

\begin{tabular}{|l|c|c|c|}
\hline \multirow{2}{*}{ Groups } & \multicolumn{3}{|c|}{ Serum triglyceride - Days post treatment } \\
\cline { 2 - 4 } & Day 15 & Day 30 & Day 45 \\
\hline Group I (NC) & $69.33 \pm 0.7^{\mathrm{aX}}$ & $72.75 \pm 1.30^{\mathrm{aX}}$ & $73.0 \pm 2.81^{\mathrm{aX}}$ \\
\hline Group II (DC) & $157.6 \pm 6.85^{\mathrm{bX}}$ & $178.72 \pm 6.83^{\mathrm{bY}}$ & $202.5 \pm 11.42^{\mathrm{bZ}}$ \\
\hline Group III (GC) & $150.93 \pm 6.06^{\mathrm{bX}}$ & $108.91 \pm 2.12^{\mathrm{cY}}$ & $83.5 \pm 2.20^{\mathrm{aZ}}$ \\
\hline Group IV U20) & $154.0 \pm 6.98^{\mathrm{bX}}$ & $109.58 \pm 3.05^{\mathrm{cY}}$ & $90.66 \pm 4.27^{\mathrm{aZ}}$ \\
\hline Group V (U40) & $153.26 \pm 6.13^{\mathrm{bX}}$ & $108.0 \pm 4.54^{\mathrm{cY}}$ & $85.1 \pm 3.65^{\mathrm{aZ}}$ \\
\hline $\begin{array}{l}\text { Group VI (U20 } \\
\text { +GC) }\end{array}$ & $151.0 \pm 4.78^{\mathrm{bX}}$ & $107.75 \pm 4.77^{\mathrm{cY}}$ & $84.52 \pm 3.53^{\mathrm{aZ}}$ \\
\hline
\end{tabular}

Values bearing different superscripts between rows within a column and capital letters within column vary significantly $(p \leq 0.05)$

Table.3 The Mean $( \pm \mathrm{SE})$ values of activities of SOD (U/min/mg protein) in the liver of treatment and control groups at different intervals of time

\begin{tabular}{|l|c|c|c|}
\hline \multirow{2}{*}{\multicolumn{1}{|c|}{ Groups }} & \multicolumn{3}{c|}{ SOD - Days post treatment } \\
\cline { 2 - 4 } Group I (NC) & Day 15 & Day 30 & Day 45 \\
\hline Group II (DC) & $14.33 \pm 1.31^{\mathrm{aX}}$ & $15.67 \pm 1.17^{\mathrm{aX}}$ & $20.67 \pm 1.33^{\mathrm{aY}}$ \\
\hline Group III (GC) & $4.67 \pm 1.02^{\mathrm{bX}}$ & $5.00 \pm 0.86^{\mathrm{bX}}$ & $4.17 \pm 0.48^{\mathrm{bX}}$ \\
\hline Group IV (U20) & $3.67 \pm 0.70^{\mathrm{bX}}$ & $6.83 \pm 0.65^{\mathrm{bX}}$ & $10.83 \pm 1.08^{\mathrm{bX}}$ \\
\hline Group V (U40) & $4.16 \pm 0.48^{\mathrm{bX}}$ & $4.01 \pm 0.87^{\mathrm{bX}}$ & $6.33 \pm 0.56^{\mathrm{bdX}}$ \\
\hline Group VI (U20 +GC) & $5.16 \pm 0.58^{\mathrm{bX}}$ & $7.83 \pm 1.19^{\mathrm{bXY}}$ & $11.16 \pm 1.02^{\mathrm{cdY}}$ \\
\hline
\end{tabular}

Values bearing different superscripts between rows within a column and capital letters within column vary significantly $(\mathrm{p} \leq 0.05)$ 
Table.4 The Mean ( \pm SE) values of activities of SOD (U/min/mg protein) in the liver of treatment and control groups at different intervals of time

\begin{tabular}{|l|c|c|c|}
\hline \multirow{2}{*}{\multicolumn{1}{|c|}{ Groups }} & \multicolumn{3}{c|}{ CAT - Days post treatment } \\
\cline { 2 - 4 } & Day 15 & Day 30 & Day 45 \\
\hline Group I (NC) & $89.83 \pm 3.16^{\mathrm{aX}}$ & $87.83 \pm 2.38^{\mathrm{aX}}$ & $85.67 \pm 2.51^{\mathrm{aX}}$ \\
\hline Group II (DC) & $42.96 \pm 2.11^{\mathrm{bX}}$ & $40.52 \pm 2.17^{\mathrm{bX}}$ & $39.16 \pm 2.09^{\mathrm{bX}}$ \\
\hline Group III (GC) & $49.45 \pm 3.32^{\mathrm{bX}}$ & $62.25 \pm 3.59^{\mathrm{cY}}$ & $77.20 \pm 2.10^{\mathrm{acZ}}$ \\
\hline Group IV (U20) & $41.46 \pm 3.29^{\mathrm{bX}}$ & $58.71 \pm 0.78^{\mathrm{cY}}$ & $67.83 \pm 3.07^{\mathrm{cdY}}$ \\
\hline Group V (U40) & $43.38 \pm 4.19^{\mathrm{bX}}$ & $51.00 \pm 1.87^{\mathrm{bcX}}$ & $74.08 \pm 4.17^{\mathrm{adY}}$ \\
\hline Group VI (U20 +GC) & $44.86 \pm 3.28^{\mathrm{bX}}$ & $53.17 \pm 3.68^{\mathrm{cX}}$ & $78.41 \pm 3.51^{\mathrm{adY}}$ \\
\hline
\end{tabular}

Values bearing different superscripts between rows within a column and capital letters within column vary significantly $(\mathrm{p} \leq 0.05)$

Table.4 The Mean $( \pm$ SE) values of activities of GPx $(\mu \mathrm{M}$ of glutathione utilized $/ \mathrm{min} / \mathrm{mg}$ protein)in the liver of treatment and control groups at different intervals of time

\begin{tabular}{|l|c|c|c|}
\hline \multicolumn{1}{|c|}{ Groups } & \multicolumn{3}{|c|}{ GPX - Days post treatment } \\
\hline Group I (NC) & Day 15 & Day 30 & Day 45 \\
\hline Group II (DC) & $8.37 \pm 0.33^{\mathrm{aX}}$ & $8.48 \pm 1.17^{\mathrm{aX}}$ & $9.59 \pm 0.54^{\mathrm{aX}}$ \\
\hline Group III (GC) & $3.10 \pm 0.21^{\mathrm{bX}}$ & $3.74 \pm 0.48^{\mathrm{bX}}$ & $4.10 \pm 0.41^{\mathrm{bX}}$ \\
\hline Group IV (U20) & $3.95 \pm 0.21^{\mathrm{bX}}$ & $5.26 \pm 0.41^{\mathrm{bX}}$ & $8.14 \pm 0.44^{\mathrm{ac} Y}$ \\
\hline Group V (U40) & $3.68 \pm 0.19^{\mathrm{bX}}$ & $4.5 \pm 0.58^{\mathrm{bX}}$ & $7.47 \pm 0.34^{\mathrm{cdY}}$ \\
\hline Group VI (U20 +GC) & $3.84 \pm 0.28^{\mathrm{bX}}$ & $5.12 \pm 0.91^{\mathrm{bX}}$ & $7.82 \pm 0.29^{\mathrm{adY}}$ \\
\hline
\end{tabular}

Values bearing different superscripts between rows within a column and capital letters within column vary significantly $(\mathrm{p} \leq 0.05)$

Fig.1

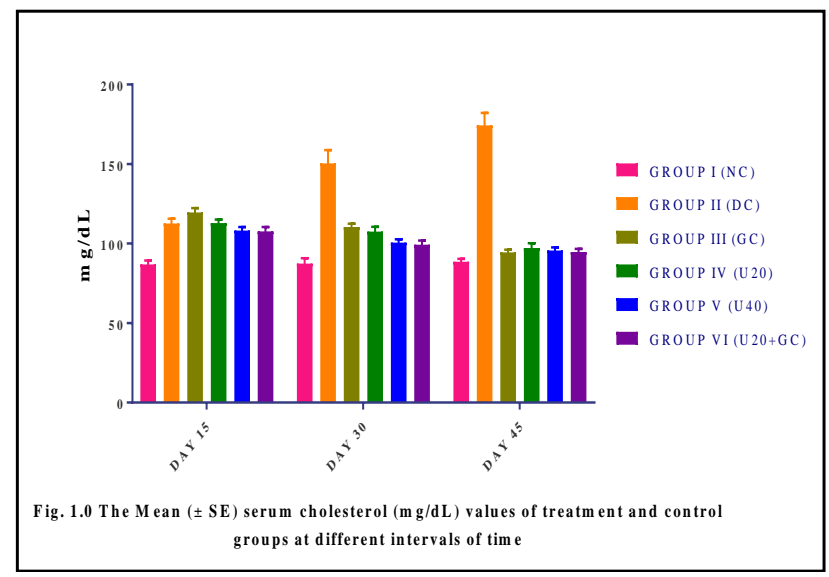


Fig.2

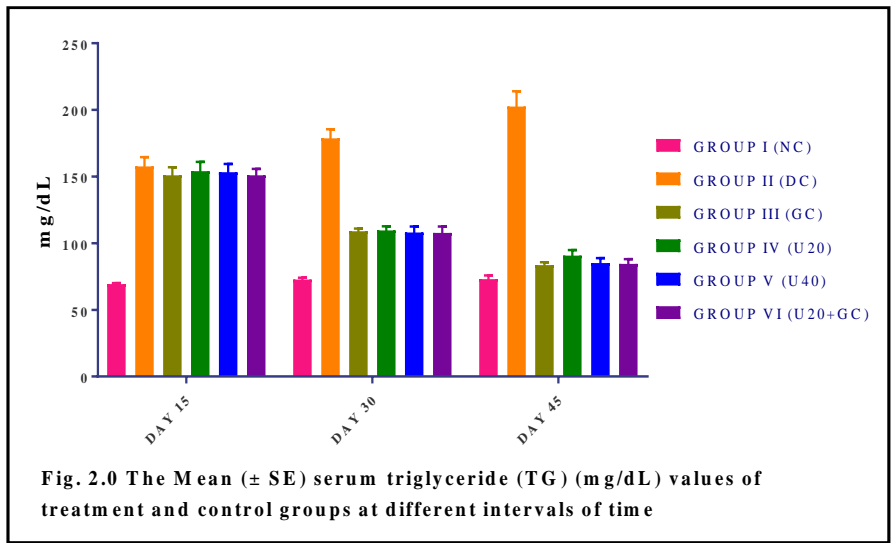

Fig.3

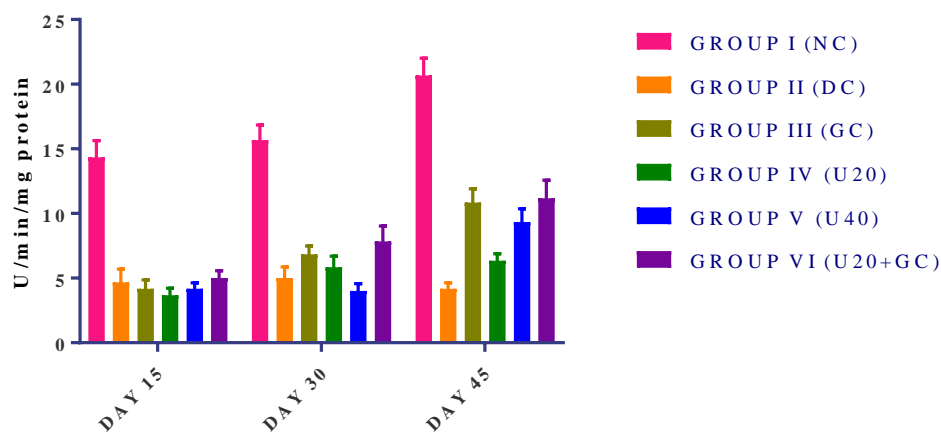

Fig: 3.0 The Mean ( $\pm \mathrm{SE})$ values of activities of $S O D(\mathrm{U} / \mathrm{min} / \mathrm{mg}$ protein $)$ in the liver of treatment and control groups at different intervals of time

Fig.4

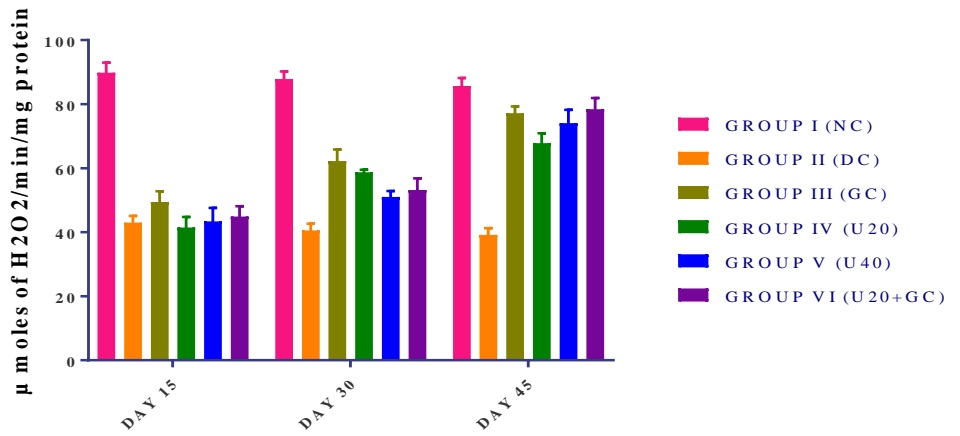

Fig: 4.0 The Mean ( \pm SE) mean values of activities of CAT $\left(\mu\right.$ moles of $\mathrm{H}_{2} \mathrm{O} 2 / \mathrm{min} / \mathrm{mg}$ protein) in the liver of treatment and control groups at different intervals of time 
Fig.5

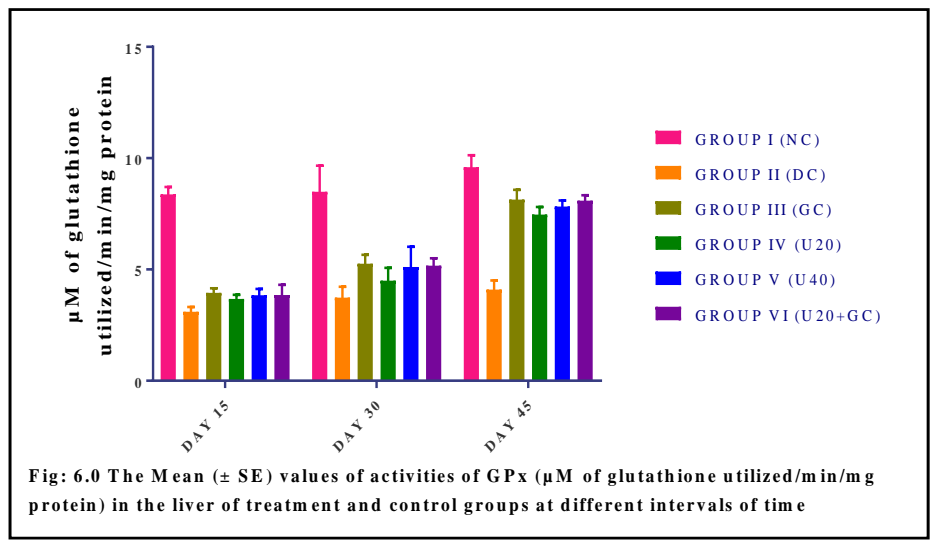

In type 2 diabetes, due to defective insulin secretion several metabolic disturbances are observed. Often, coexistence of metabolic disturbances and oxidative stress characterized by lipid peroxidation and decrease in antioxidants levels are observed ${ }^{15}$. The mean $( \pm S E)$ values of serum cholesterol and triglyceride levels in the diabetic control group were found to be significantly higher compared to normal control group in the present study throughout the experimental period, indicating hyperlipidemia.

The increase in triglyceride may be due to insulin deficiency which results in deranged metabolic process with decreased glucose utilization for energy purpose. This energy starvation induces mobilization of fatty acids from adipose tissue to liver, wherein their conversion to triglyceride and cholesterol occurs in excess contributing for hypertriglyceridemia and hypercholesterolaemia, respectively. In addition, diminished expression of LDL receptors due to chronic insulin deficiency might also be contributing to increased LDLcholesterol value in diabetes and insulin deficiency, which increases excessive breakdown of adipose store by stimulation of lipase leading to increased mobilisation of fatty acids for energy purpose and their excessive accumulation in liver after excess esterification to triglycerides and conversion to cholesterol ${ }^{16-20}$.In the present study, there was significant reduction in the concentration of SOD, CAT and GPx in the liver of diabetic rats from day 15 to day 45 of experimental study. Similar findings have been recorded in alloxan and STZ induced diabetic rat models by several workers ${ }^{19,21}$.

The current study showed persistent hyperglycemia leading to production of free radicals or impaired antioxidant defenses via several mechanisms ${ }^{22-24}$. Decline in the activities of antioxidant enzymes in the liver of diabetic animals indicated the extent of free radical induced damage due to STZ induced hyperglycemia ${ }^{25-26}$. During diabetes, free radical generation is associated with autooxidation of glucose, impaired glutathione metabolism, alterations in the antioxidant enzymes and formation of lipid peroxides ${ }^{27}$

In the present study, Group III diabetic rats were treated daily with glibenclamide at a dose rate of $600 \mu \mathrm{g} / \mathrm{kg}$ from day 3 onwards. In the present study, the serum cholesterol and serum triglyceride levels were significantly $(\mathrm{P} \leq 0.001)$ reduced in the glibenclamide treated animals compared to diabetic control rats which clearly indicated 
that the treatment with glibenclamide reduced hyperlipidaemia in diabetes. In one study, the researchers observed an improvement in triglyceride levels in Type-2 DM with Glibenclamide treatment, reported that alleviation of hypertriglyceridemia was due to acute reduction in triglyceride of intestinal origin and not with the VLD lipoprotein sub fraction levels ${ }^{28}$.

In glibenclamide treated rats, the serum cholesterol and serum triglyceride levels were significantly $(\mathrm{P} \leq 0.001)$ reduced as compared to diabetic control animals on $30^{\text {th }}$ and $45^{\text {th }}$ day of the experiment. The mean values of SOD, CAT and GPx activities in the liver of glibenclamide treated rats were improved compared to diabetic rats. However, the values were lesser compared to the other treated groups individually or in combination as plants have been the rich source of several antioxidants. Similar observations were also recorded by many earlier workers ${ }^{29-30}$. In spite of hypoglycaemic nature of glibenclamide, it was opined that glibenclamide cannot effectively alleviate the oxidative stress completely $^{31}$. The level of antioxidants is indirectly proportional to free radical concentration. The sustained oxidative stress in induced diabetes in the present study could be responsible for the low concentration of antioxidants compared to other treatment groups. However, the improvement observed in antioxidant level and lipid values could be attributed to the hypoglycemic effect of glibenclamide by increasing the release of insulin thereby reversing the diabetes induced changes and increase liver antioxidant enzymes $^{29}$.

There was a significant progressive decrease in the mean $( \pm S E)$ serum cholesterol and triglyceride values in UMB @ 20mg/ $/ \mathrm{kg} \mathrm{b}$. wt.and $40 \mathrm{mg} / \mathrm{kg} \mathrm{b}$. wt. treated rats on $15^{\text {th }}$ to $45^{\text {th }}$ day post-treatment, respectively. In comparison with glibenclamide, Group IV
(UMB@20 mg/kg b. wt.), Group IV (UMB @ $40 \mathrm{mg} / \mathrm{kg} \mathrm{b}$. wt.) and combination Group VI, the mean cholesterol and triglyceride values did not vary significantly throughout the experimental study period.

In Type $2 \mathrm{DM}$, insulin secretion is defective and insufficient to compensate for insulin resistance which may improve with weight reduction and/or pharmacological treatment of hyperglycemia but is seldom restored to normal $^{32}$.

The levels of serum lipids are elevated in DM and such an elevation represents a risk factor for coronary heart disease ${ }^{33}$. The abnormal high concentration of serum lipids in diabetic subjects is mainly due to increase in the mobilization of free fatty acids from fat deposits since insulin is required for the inhibition of hormone-sensitive lipase ${ }^{34}$. On the other hand, glucagon and other hormones enhance lipolysis. The marked hyperlipidaemia that characterizes the diabetic state may, therefore, be regarded as a consequence of uninhibited actions of lipolytic hormones on the fat deposits ${ }^{35}$. In the present study, diabetic rats treated with UMB and Glibenclamide reduced the serum total cholesterol and triglycerides back to near normal levels, which could be due to an increase in insulin secretion, which, in turn, inhibits hormone sensitive lipase and increases the utilization of glucose and thereby decreasing the mobilization of free fatty acids from the fat depots ${ }^{9}$.

UMB supplementation caused significant anti hyperlipidemia effect by increasing the hepatic $\beta$-oxidation and inhibition of phosphatidate phosphohydrolase (PAP) activity, a key enzyme in triglyceride synthesis, was significantly lowered. Further, it was observed that UMB supplementation caused an increase in plasma adiponectin levels ${ }^{36}$. 
The present study shows a downward trend in the values of triglycerides and Cholesterol in UMB treated groups. These results are in agreement with the previous reports ${ }^{37}$, who reported that adiponectin activate AMPK, which is the 'metabolic master switch' controlling pathways of hepatic ketogenesis, cholesterol synthesis and triglyceride synthesis. Further, it was reported that there was a significant inverse relationship between plasma triglyceride and serum adiponectin levels $^{38}$.

The reduction in the triglycerides and cholesterol in UMB treated groups could be due to UMB induced modulation of hepatic lipid metabolism and the antioxidant defense system along with increasing adiponectin.

The increase of free radical mediated toxicity is well documented in clinical diabetes ${ }^{39}$ and STZ-diabetic rats ${ }^{40}$. Free radicals react with lipids and causes peroxidative changes that result in enhanced lipid peroxidation ${ }^{41}$.

There was significant improvement in the mean activities of antioxidant enzymes in liver of UMB treated rats compared to diabetic animals and were comparable with glibenclamide control and combination treated rats.

The antioxidant activity of UMB is well documented $^{42}$. Several researchers also concluded through their study that UMB possessed good antioxidant property by exerting rapid protective effect against lipid peroxidation through scavenging free radicals and elevating both nonenzymic and enzymic antioxidants as evidenced by improved redox homeostasis and decreased lipid peroxidation and opined that use of which may protect from the risk of diabetic complications ${ }^{9,43}$.

Several studies showed the activities of SOD, CAT and GPx being decreased in diabetic rats as reported earlier ${ }^{44}$ which could be due to increased utilization for scavenging free radicals. Treatment with UMB and glibenclamide has reversed the activities of these enzymatic antioxidants which could be a result of decreased lipid peroxidation and or decreased utilization ${ }^{10}$.

The improvement in the overall condition in UMB treated groups could be due to effective management of hyperglycaemia thereby reducing the alteration in metabolism of carbohydrate, lipid and protein ${ }^{45}$.

Similarly, UMB was also reported to have anti-oxidant effect on chronic alcohol induced liver damage by inhibiting TLR-4 signaling pathway and improving antioxidant system ${ }^{36}$. It has also been reported that UMB pretreatment showed a significant inhibition of intra-cellular ROS production and also scavenges $-\mathrm{OH}$ radicals in a concentration dependent manner ${ }^{7}$.

Similar findings on the antioxidant and hepatoprotective properties of UMB was reported and opined that, UMB alleviated oxidative damage in the liver by inhibiting HMGB1-induced inflammatory response and concurrent activation of Nrf2-mediated signal pathway for boosting the cellular anti-oxidant profile $^{46}$.

Upregulation of antioxidant profiles was reported after administration of UMB, which lead to diminished malondialdehyde and nitric oxide levels, boosted reduced glutathione and antioxidant enzymes, which was largely mediated through upregulation of the expression of PPAR $\gamma$ and attenuation of oxidative stress $^{47}$.

Several coumarins including UMB played a role in activating Nrf2 signaling pathway which played a vital role in the protection against cell injury induced by oxidative stress 
and electrophiles. Since, the crosstalk between the Nrf2/ARE signaling and NF- $\kappa \mathrm{B}$, represented the main underlying mechanism by which Nrf2 exerted its anti-inflammatory activities as well as the antioxidant properties mediated via Nrf2 modulation ${ }^{48}$.

In conclusion the aadministration of UMB alone $(20 \mathrm{mg} / \mathrm{kg}$. b. wt. and $40 \mathrm{mg} / \mathrm{kg}$. b. wt.) possessed anticholesterolemic and antitriglyceridemic properties. The significant improvement in anti-oxidant profile in the current study could be attributed to bioactivity of umbelliferone

\section{Acknowledgement}

Authors are thankful to the Head of the Department, Department of Veterinary pathology, Dean, Veterinary College, Bangalore, KVAFSU and Ms. Medha Karnik, (JRF- for technical assistance) for providing facilities to carry out the present study.

\section{References}

American Diabetes Association, 2005. Diagnosis and classification of diabetes mellitus. Diabetes Care., 28: S37-S42.

Andallu, B., Varadacharyulu, N.C.H., 2003. Antioxidant role of mulberry (Morus indica L.) leaves in streptozotocin diabetic rats. Clinicachimica Acta, 338, $3-10$.

Caliborne, A.L., 1985. Assay of catalase: Handbook of oxygen radical research. Ed. Greenward, R.A., CRC Press

Chris, I.C., Ungureanu, M.I., Marton, A., Simedrea, R., Muresan, A., Postescu, I.D. and Decea, N., 2009. Antioxidant effects of a grape seed extract in a rat model of diabetes mellitus. Diab. Vasc. Dis. Res., 6(3): 200-204

Davidson, M.B., 1981. Diabetes Mellitus, Diagnosis and Treatment. Hoboken, New Jersey: John Wiley and Sons; p. 109

Elmali, E., Altan, N. and Bukan, N., 2004.
Effect of the sulphonylurea glibenclamide on liver and kidney antioxidant enzymes in streptozotocin-induced diabetic rats. Drugs R D., 5: 203-208

Erejuwa, O.O., Sulaiman, S.A., Wahab, M.S.A., Sirajudeen, K.N., Salleh, S. and Gurtu, S., 2011., Glibenclamide or metformin combined with honey improves glycemic control in streptozotocin-induced diabetic rats. Int. J. Biol. Sci., 7: 244-252

Girotti, M.W., 1985. Mechanisms of lipid peroxidation. Free Radical Biology and Medicine 1, 87-95.

Goodman, L.S. and Gilman, A., 1985. The Pharmacological Basis of Therapeutics, 7th ed. New York: MacMillan, p. 490.

Hassanein, E., Sayed, A. M., Hussein, O. E., and Mahmoud, A. M., 2020. Coumarins as Modulators of the Keap1/Nrf2/ARE Signalling Pathway. Oxid. Med. Cell. Longev, 1675957.

Hoult, J.R.S., PAYA, M., 1996. Pharmacological and biochemical actions of simple coumarins: natural products with therapeutic potential. General Pharmacology 27, 713-722.

International Diabetes Federation. IDF Diabetes Atlas. 7th ed. Brussels, Belgium: International Diabetes Federation; 2015.

Izadi, V., Farabad, E., and Azadbakht, L., 2013. Epidemiologic evidence on serum adiponectin level and lipid profile. Int $J$ Prev Med, 4(2), 133-140.

Kaleem, M., Asif, M., Ahmed, Q.U. and Bano, B., 2006. Antidiabetic and antioxidant activity of Annona squamosa extract in streptozotocin-induced diabetic rats. Singapore Med. J., 47(8): 670-675

Mahdi, A.A., Anu, C., Rajkumar, S., Shukla, S.L.C., Mishra. and Sohail, A., 2003. Effect of herbal hypoglycemic agents on oxidative stress and antioxidant status in diabetic rats. Indian J. Clini. Biochem., 18(2): 8-15

Mahmoud, A. M., Hozayen, W. G., Hasan, I. H., Shaban, E., and Bin-Jumah, M., 2019. Umbelliferone Ameliorates $\mathrm{CCl}_{4}$-Induced Liver Fibrosis in Rats by Upregulating PPAR $\gamma$ and Attenuating Oxidative Stress, 
Inflammation, and TGF- $\beta 1 / \mathrm{Smad} 3$ Signalling. Inflammation, 42(3), 1103 1116.

Manjunatha, S.S., 2017. Pathomorphological studies on induced diabetes in rats and evaluation of antidiabetic efficacy of aloe vera and murraya koenigii plant extracts. $\mathrm{Ph} . \mathrm{D}$. thesis, KVAFSU, Bidar, Karnataka, India

Marakku, L., 1995. Epidemiology of diabetic dyslipidemia. Diabetes rev., 3: 408-422

Maritim, A.C., Sanders, R.A. and Watkins, J.B., 2003. Diabetes, oxidative stress, and antioxidants: a review. J. Biochem. Mol. Toxicol., 17(1): 24-38

Marklund, S.L. and Marklund, G., 1974. Involvement of the superoxide anion radical in the autoxoidation of pyrogallol and a convenient assay for superoxide dismutase. Eur. J. Biochem., 47: 469-474

Mazimba, O., 2017. Umbelliferone: Sources, chemistry and bioactivities review, Bulletin of Faculty of Pharmacy, Cairo University, 55(2): 223-232.

Mendez, J.D. and BALDERAS, F., 2001.Regulation of hyperglycemia and dyslipidemia by exogenous L-arginine in diabetic rats. Biochimie.,83(5): 453-458

Nafisa, P.C.F., Chakradhar V.L., Vandana, S.P. and Suresh, R.N., 2007. An experimental evaluation of the antidiabetic and antilipidemic properties of a standardized Momordica charantia fruit extract. BMC Complement. Altern. Med.,7(29):1-8

Nagabhushan, C. 2020. Studies on induced diabetes in rats with special emphasis on combined efficacy of Gymnemasylvestrae and Eugenia jambolana. M.V.Sc. thesis, KVAFSU, Bidar, Karnataka, India

Nourooz-ZADEH, J., Rahimi, A., TajaddiniSarmadi, J., Tritschler, H., ROSEN, P., Halliwell, B., Betteridge D.J.,1997. Relationships between plasma measures of oxidative stress and metabolic control in NIDDM. Diabetologia., 40(6) 647-653.

Rajnish, G. and Radhey, S.G., 2009. Effect of Pterocarpus marsupium in Streptozotocin-induced hyperglycemic state in Rats: comparison with glibenclamide. J. Diabetologia Croatica., 38(2): 38-45

Ramesh, B and Pugalendi, K.V., 2006b. Antioxidant role of Umbelliferone in STZ-diabetic rats. Life Sci., 79(3):306-10.

Ramesh, B and Pugalendi, K.V., 2006c. Impact of umbelliferone (7-hydroxycoumarin) on hepatic marker enzymes in streptozotocin diabetic rats. Indian J Pharmacol, 38:20910

Ramesh, B and Pugalendi, K.V.,2005. Impact of umbelliferone on erythrocyte redox status in STZ-diabetic rats. Yale $\mathrm{J}$ Biol Med.,78:133-40.

Ranjit, U., Rajendra, P., Shashank, R. J., Viswanathan, M., 2017. Type 2 Diabetes: Demystifying the Global Epidemic. Diabetes Jun, 66 (6) 1432-1442.

Rashmi, N.G., Bannimath, G., and Huded, S.P., 2017. Herb-drug Interaction: Effect of Poly-Herbal Formulation on Glibenclamide Therapy in Patients with Type-2 Diabetes Mellitus, Pharm Methods, 8(1): 62-70.

Resmi, C.R., Venukumar, M.R. and Latha, M.S., 2006. Antioxidant activity of Albizzia lebbeck (Linn.) Benth. In alloxan diabetic rats. Indian J. Physiol. Pharmacol., 50(3): 297-301

Rhoades, G.G., Gulbrandse, C.L., and KAGAN, A., 1976. Serum lipoproteins and coronary artery diseases in a population study of Hawaii, a Japanese man. N Engl. J Med., 294:293-8.

Rotruck, J.T., Pope, A.L., Ganther, H.E., Swanson, A.B., Hafeman, D.G. and Hockstra, W.G., 1973. Selenium: Biochemical role as a component of glutathione peroxidase. Sci., 179: 588-598

Sathishsekar, D. and Subramanian, S., 2005. Antioxidant properties of Momordica charantia(bitter gourd) seeds on streptozotocin induced diabetic rats. Asia Pac. J. Clin. Nutr., 14(2): 153-158

Saxena, A.M., Bajpai, M.B., Murthy, P.S. and Mukherjee, S.K., 1993. Mechanism of blood sugar lowering by a swerchirincontaining hexane fraction (SWI) of Swertia chirayita. Indian J. Exp. Biol., 
31(2): 178-181.

Sim, M. O., Lee, H. I., Ham, J. R., Seo, K. I., Kim, M. J., and Lee, M. K., 2015. Antiinflammatory and antioxidant effects of umbelliferone in chronic alcohol-fed rats. Nutrition research and practice, 9(4), 364-369.

Sim, M. O., Lee, H. I., Ham, J. R., Seo, K. I., KIM, M. J., and LEE, M. K., 2015. Antiinflammatory and antioxidant effects of umbelliferone in chronic alcohol-fed rats. Nutrition research and practice, 9(4), 364-369.

Singh, P.K., Baxi, D., Banerjee, S. and Ramachandran, A.V., 2010.Therapy with methanolic extract of Pterocarpus marsupium Roxb and Ocimum sanctum Linn reverses dyslipidemia and oxidative stress in alloxan induced type I diabetic rat model. Exp. Toxicol. Pathol., 64(5): 441-448.

Singh, P.P., Ambika and Chauhan, S.M., 2012. Activity-guided isolation of antioxidant xanthones from Swertia chirayita (Roxb.) H. Karsten (Gentianaceae). Nat. Prod. Res., 26(18): 1682-1686.

Skrapari, I., Perrea, D., Ivannidia, I., Karabinas, A.P., Elisaf, M., Tselepis, A.D., Karagiannaws, P. and Katsilambron., 2001. Glibenclamide improves postprandial hypertriglyceridemia in type2 diabetic patients by reducing chyloicrones but not the very low density lipoproteins subfration levels. Diabet Med., 18(10): 781-785.

Steinberg GR and Kemp BE. AMPK in Health and Disease, 2009. Physiol Rev; 89: 1025-1078.

Valko, M., Leibfritz, D., Moncol, J., Cronin, M.T., Mazur, M. and Telser, J., 2007. Free radicals and antioxidants in normal physiological functions and human disease. Int. J. Biochem. Cell Biol., 39(1): 44-84

Venkatesh, S., Dayanand, G.R., Madhava, B. R., Ramesh, M., APPA Rao, A.V.N., 2003. Antihyperglycemic activity of Caralluma attenuata, Fitoterapia, 74(3) Pages 274-279.

Venkatesh, S., Reddy, B.M., Reddy, G.D., Mullangi, R., and Lakshman, M. 2010. Antihyperglycemic and hypolipidemic effects of Helicteresisoraroots in alloxaninduced diabetic rats: a possible mechanism of action. J. Nat. Med., 64(3): 295-304

Wohaieb, S.A., Godin, D.V., 1987. Alteration in free radical tissue defense mechanisms in streptozotocin diabetes in rats: effect of insulin treatment. Diabetes, 36, 10141018.

WU, F.J. and Sheu, S.J., 1992. Analysis and processing of Chinese herbal drugs: the study of Fructus Aurantii Immaturus (Chin.). Chin Pharm J., 44:257-63.

Yin, J., Wang, H., and LU, G., 2018. Umbelliferone alleviates hepatic injury in diabetic $\mathrm{db} / \mathrm{db}$ mice via inhibiting inflammatory response and activating Nrf2-mediated antioxidant. Bioscience reports, 38(4), BSR20180444.

\section{How to cite this article:}

Anjan Kumar, K. R., M. L. Satyanarayana, H. D. Narayanaswamy, Suguna Rao, N. Prakash and Ramesh, P. T. 2020. Anticholesterolemic, Antitriglyceridemic and Antioxidative Activity Effect of Umbelliferone (Coumarin) in Streptozocin Treated Diabetic Rats Int.J.Curr.Microbiol.App.Sci. 9(09): 1-13. doi: https://doi.org/10.20546/ijcmas.2020.909.001 